\title{
Methods for preparation of corroded steel specimens for mechanical testing
}

\author{
Nikolay Nikolov ${ }^{1, *}$, Yordanka Marcheva ${ }^{2}$ and Veselin Tsonev ${ }^{1}$ \\ ${ }^{1}$ Technical University - Sofia, "Strength of materials" Department, 8 "Kliment Ohridski” Blvd., 1000 Sofia, Bulgaria \\ ${ }^{2}$ Technical University - Sofia, "Chemistry” Department, 8 "Kliment Ohridski” Blvd., 1000 Sofia, Bulgaria
}

\begin{abstract}
Steel parts and structures are often used in an aggressive environment, which causes corrosion. Corrosion leads to deterioration of the mechanical properties of steel in two ways. First, it reduces the area of the carrying cross sections. Second, it increases surface defects, which are stress concentrators. Therefore, it is necessary to study the impact of corrosion on the mechanical properties of steel. The paper reviews the methods for causing corrosion of steel specimens for mechanical testing. The impact that the corrosion method and the degree of corrosion have on the mechanical properties of steel is also discussed.
\end{abstract}

\section{Introduction}

Mechanical properties of traditional construction materials have been studied closely as the structures behaviour depend on them. When these materials are applied in new environments and in new conditions, often their mechanical properties have not been studied enough.

An important factor impacting the mechanical properties of metals is corrosion, which occurs as a result of the reaction between the metal and the surrounding environment. Corrosion reduces cross sections and creates stress concentrators, which negatively affect the load bearing capacity of a particular members and of the structure as a whole. Furthermore, corrosion has significant impact on the deformation behaviour and the destruction of metals - it might change the type of destruction from ductile to brittle. That can lead to an unexpected behaviour and even to an unexpected destruction of the structure.

The study of such an effects is done using specimens, which are first subjected to the corrosion impact, and then to mechanical tests. The information obtained is needed to prepare an adequate analysis of the strength and deformations of the corroded structures. The results can be used to assess safety and their residual resource.

The aim of the present study is to review the methods that cause corrosion of steel specimens for mechanical testing. It will also analyse the impact of the corrosion method and the degree of corrosion on the mechanical properties.

\section{Types of corrosion}

The choice of a corrosion test method largely depends on the type of working conditions. There are a number of factors which cause the corrosion of metals. Depending on the mechanism in which the process occurs, corrosion is divided into two main types - chemical (gas corrosion and corrosion in non-electrolytes) and electrochemical (in electrolyte environments - atmospheric, underground, in cracks, etc., enlisted in ISO 8044-94).

Exploitation corrosion occurs as the result of typical working conditions. Exploitation corrosion is a slow process and it can take dozens of years. Thus, it is difficult to get a representative group of corroded specimens for mechanical testing. In order to accelerate the process the specimens are subjected to an environment which is considerably more aggressive than their natural working environment. That type of corrosion is called accelerated corrosion. When creating conditions that imitate the real ones, model corrosion is achieved.

Accelerated corrosion is caused artificially. It differs from exploitation corrosion and its consequences (like the mechanical behaviour of the material) can also be different.

Depending on its impact on the material, we distinguish between two types of corrosion, with a number of subgroups within them:

- uniform corrosion - it covers the whole surface of the surface under examination;

- local corrosion - it affects only some spots on the surface and can be spot corrosion, ulcer corrosion, pitting, intercrystaline, transcrystaline, etc. Pitting corrosion is highly localized corrosion and results from the destruction of a protective (passive) layer.

Depending on the environment in which the corrosion process occurs, we distinguish between atmospheric, soil, sea and other types of corrosion. The most common type is atmospheric corrosion. It depends on many external factors - humidity, temperature, winds, availability of salts, $\mathrm{pH}$ and other conditions related to the particular climatic specifics.

Steel and reinforced concrete structures in the open air are under the greatest threat. Usually, steel structures are

\footnotetext{
* Corresponding author: nyky@tu-sofia.bg
} 
protected with anti-corrosion coatings and/or by means of other methods. However, anticorrosion coatings have limited operating life and when it is reached, expanding with time uneven corrosion occurs, if the coatings are not renewed. That is a considerable problem for reinforced concrete structures since the reinforcement steel used in them easily corrodes and concrete does not protect it enough from the impacts of the environment. Moreover, the products of corrosion create mechanical stress on the concrete, which leads to cracks in it and to weakened connection between concrete and steel [1].

\section{Evaluation of mechanical properties with corrosion in a natural environment}

Atmospheric corrosion in steel and reinforced concrete structures is a slow process. When we have to evaluate the mechanical properties of real structures, which have operated in an aggressive environment for a long time and have corroded, the only possible method of obtaining specimens is to take them from the structure. Usually, steel rods are taken from reinforced structures, which have been exposed to a natural or artificial environment for a long time (20-40 years) $[2,3]$ or parts are cut out from steel structures that have operated in similar conditions [4]. When there is no control group of specimens, which have not been exposed to corrosion, the comparison and evaluation of the mechanical properties are made with specimens, which have undergone corrosion of a different type and to a different extent.

With structures which have already been in operation that method gives a clear idea of the consequences of the impact of corrosion. A drawback of the method is the lack of control specimens to use in order to identify the initial properties of the material. Sometimes cutting is needed and the properties of the material can change.

Fig. 1 shows conditional tensile strain curves of a large flat specimen cut out from a bridge exposed to atmospheric corrosion after about 100 years of operation [4]. The specimens have overall, pitting or local corrosion. The impact of corrosion on yield strength, tensile strength and plastic properties is big.

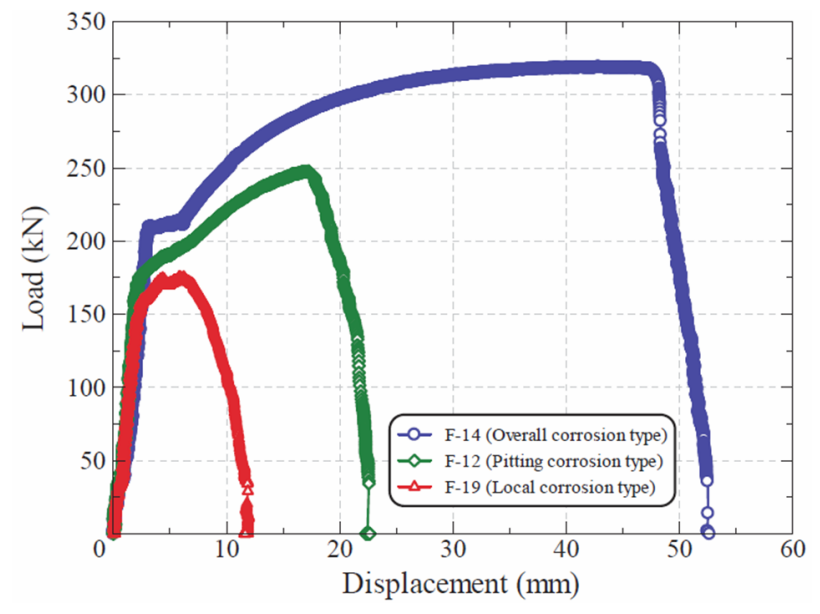

Fig. 1. Tensile strain curves of specimens from natural environment corroded structure [4].
Fig. 2 presents the conditional tensile strain curves of cylindrical specimens exposed to the impact of sea water for a period of 0,6 and 12 months [5]. Although it is not so explicit, due to the shorter period of time, the impact is similar to that in Fig. 1. By extending the period of exposure, yield strength, tensile strength and total deformation to fracture decrease.

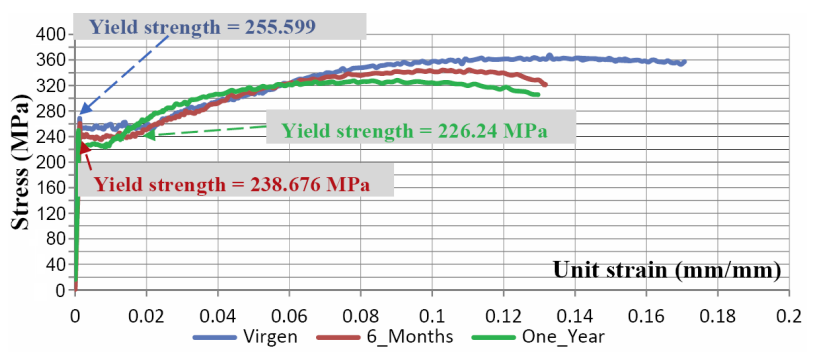

Fig. 2. Conditional curves of tensile strain of natural environment corroded specimens [5].

Obtaining corroded specimens from exposure to a natural working environment is not applicable with new structures as it would take as long as their operating life. Thus, it is necessary to use accelerated methods. This is the case in most of the numerous studies of corrosion impact on the mechanical properties of steel.

\section{Choosing accelerated corrosion method}

Atmospheric corrosion is usually uneven in nature and creates spots, pits and pittings. The most widely used methods of corrosion are salt mist and immersion in sodium chloride solution. They provide uniform distribution of corrosion damage, which affects the mechanic behaviour of corroded specimens.

Corrosion impact on the tensile strain curve of steel fibres is studied in [6]. Two corrosion methods are usedcyclic wetting/drying method and galvanostatic method. With the former method there is pitting corrosion, with the latter one there is relatively uniform corrosion. The tensile strain curves are shown in Fig. 3.

Fig. 3 shows that the accelerated corrosion method greatly impacts the mechanical properties. Pitting results in brittle behaviour. That impact is softer with uniform electrochemical corrosion. The findings are similar to studies of ribbed reinforcing steel bars [7].

Comparative studies $[6,7]$ indicate that the methods of accelerated corrosion have to be selected very carefully. Methods which create non-uniform damage are as a whole more complex and require more time, funds and efforts but are often considerably closer to the real operational environment.

\section{Accelerated corrosion methods}

\subsection{Immersion in corrosive solution}

This is technically the easiest accelerated corrosion method. The time needed to reach the desired extent of corrosion depends on the chemical composition of the 
solution and the corrosion resistance of the metal. A study [5] used natural sea water, the duration of the experiment was one year and tensile strength of steel decreased by $14.5 \%$. In [8] $20 \%$ solution of $\mathrm{NaCl}$ and flat specimens with a cross section of $20 \times 4 \mathrm{~mm}$ are used. For 10 days there was a loss of weight by $36-56 \%$ (depending on the test material), which led to a decrease in yield strength by $17-42 \%$ and in tensile strength by $32-41 \%$.

As a whole this is not a preferred method. The speed of corrosion is quite low especially with cylindrical specimens and solutions similar to those in the natural working environment (for example $3.5 \% \mathrm{NaCl}$ ). It is preferred to accelerate the process, for example by means of an electric circuit.
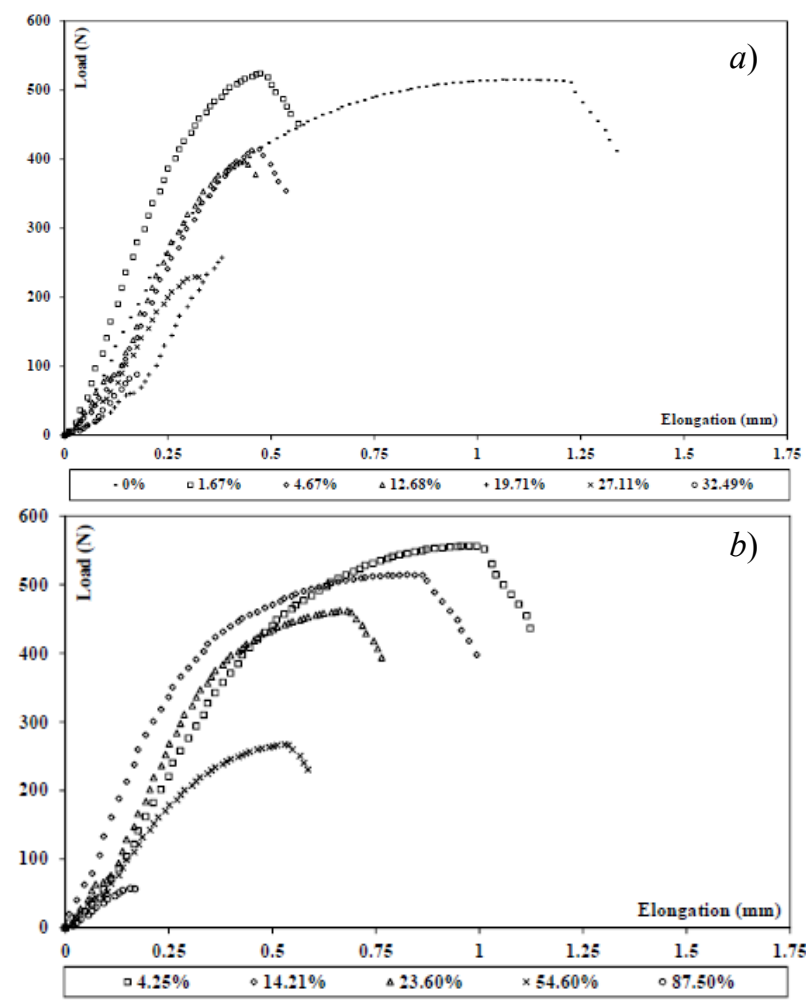

Fig. 3. Tensile strain curves of corroded specimens: a) wetting/drying method; b) galvanostatic method [6].

\subsection{Galvanostatic method}

Acceleration of the corrosion process is carried out by using of direct current and anodic dissolution of steel. The specimen is connected to the positive pole of the source (anode), and a plate of stainless steel or another inert metal is connected to the negative pole. The method is called galvanostatic. Usually a $5 \% \mathrm{NaCl}$ solution and $0.1 \div 20$ $\mathrm{mA} . \mathrm{cm}^{-2}$ current density are used.

In [6] the desired loss of mass is $2 \div 80 \%$. It is achieved by applying direct current $I$, A for a period of time $t, \mathrm{~s}$, defined by Faraday's law:

$$
t=\frac{\eta W z F}{M I} ; \quad I=A \times i \times 10^{-3},
$$

where $W$ is the initial weight of the steel wire, $g ; z$ is the ion valence $\left(z=2.5\right.$ is the average value for $\mathrm{Fe}^{2+}$ and $\mathrm{Fe}^{3+}$ of the corrosive products); $F=96.5{\mathrm{C} . \mathrm{mol}^{-1}}^{-1}$ is the Faraday constant; $M=56 \mathrm{~g} \cdot \mathrm{mol}^{-1}$ is the atomic mass of ferric ion; $A$ is the surface area in $\mathrm{cm}^{2}$.

In order to obtain precision, the current $I$ is regularly checked and corrected of the base of current density and the remaining area of the surface $A$ :

$$
A=2 \sqrt{\frac{\pi l}{\rho} W(1-\eta)},
$$

where $\rho=7.9 \mathrm{~g} / \mathrm{cm}^{3}$ is steel density and $l$ is the length of the test area in $\mathrm{cm}$.

The corroded specimens are shown in Fig. $4 a$. Corrosion is uniform. Fig. $4 b$ shows the same type of specimens subjected to cyclic corrosion testing method (CCT-method). Corrosion is non-uniform, with a great number of pittings.
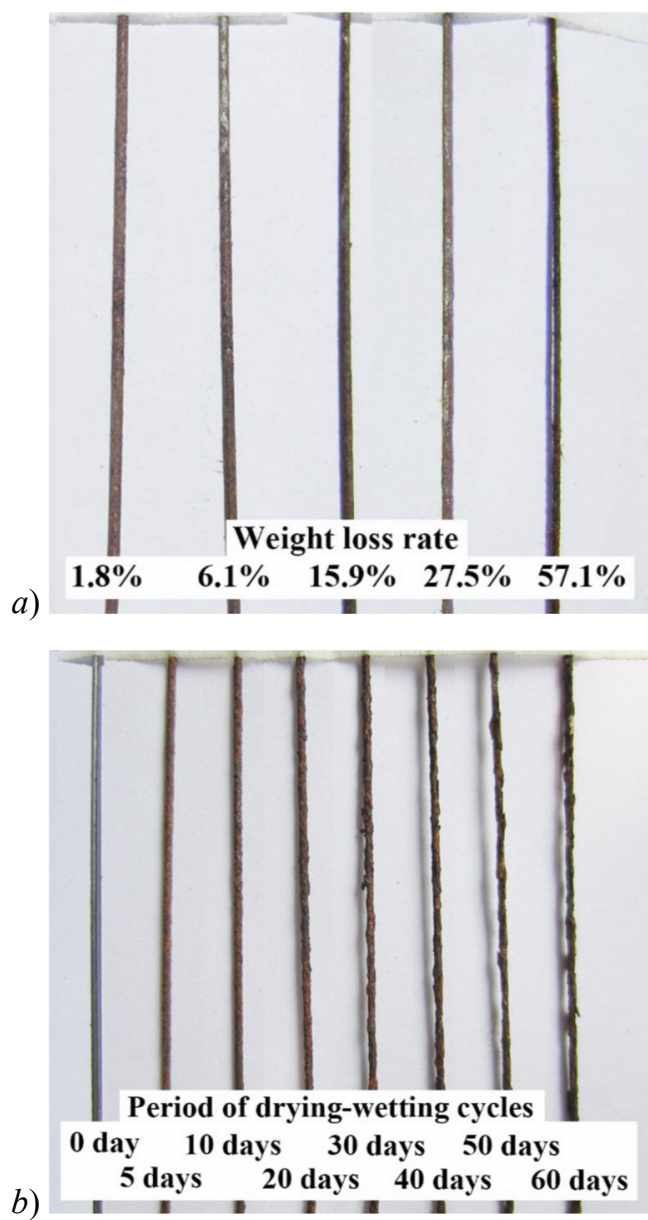

Fig. 4. Corroded specimens obtained with the galvanostatic method (a) and the CCT-method (b) [6].

\subsection{Corrosion in salt mist}

In the study of the atmospheric corrosion we can use both natural and artificial atmosphere. In spite of the difficulties and the long duration of the study, artificial atmosphere has advantages and is preferred by some researchers. For example in [2, 3] the duration of corrosion impact is dozens of years in chloride environment with two types of load. For comparison, here is also a control group of specimens, which have not been subjected to corrosion. 
The simplest and most widely used method of causing corrosion in artificial atmosphere is the method of salt mist (Salt Spray Test). The method was first used in 1914, and in 1939 it was standardized and designated as ASTM B117 [9]. The standard covers all aspects of the equipment, procedure and conditions needed to create and maintain the testing environment. Salt mist is produced with special automatically operated chambers. The European analogue is ISO 9227:2017.

Studies [2, 3] have carried out a series of tests, using ASTM B117. The $\mathrm{NaCl}$ solution used is $5 \%(\mathrm{pH} 6.5 \div 7.2)$ at a temperature of $35^{\circ} \mathrm{C}$. The corroded specimens are taken out of the chamber, washed in running water and dried in the air. The corrosion products removal is done in accordance with ASTM G1-90. The specimens are subjected to a tensile test.

The formation of an oxide layer (rust) on the surface of the metal leads to loss of mass. It is determined by weighing the material with an analytical balance before and after the experiment. Mass loss due to corrosion is calculated with the formula:

$$
\Delta m=\frac{m_{0}-m_{c}}{m_{0}} 100 \%,
$$

where $m_{0}$ is the mass of the non-corroded specimen (initial mass), and $m_{\mathrm{c}}$ is the end mass of the corroded specimen (after cleaning).

Stereoscopic examination of the clean specimen surfaces [2] shows that after 10 days of exposure to salt mist pittings start to form on the surface. The corrosion attack increases in size and depth with increasing exposure time. For a period of 60 days mass loss is about $11 \%$. Assuming the oxide layer is uniformly spread on the specimen, these results can be used to calculate the decrease in the nominal diameter of a cylindrical specimen during testing. Reduced diameter $d_{r}$ is calculated with the formula [3]:

$$
d_{r}=d \sqrt{1-a},
$$

where $a$ is the measured mass loss, and $d$ is the nominal diameter of a non-corroded specimen.

A study [3] examined the correlation of loss mass as a function of the duration of salt spray testing $t$. The correlation is shown in Fig. 5 and has been approximated through Weibull's function:

$$
d=C_{1}+\frac{C_{2}-C_{1}}{e^{\left(\log t / C_{3}\right)^{C_{4}}}},
$$

where $C_{1}$ to $C_{4}$ are constant values given in [3].

Although it is widely accepted that salt spray qualitatively simulates natural corrosion on the coast, that environment is quite aggressive and causes very strong corrosion attack for a short time. So far no direct correlation between accelerated salt spray test and the natural corrosion process has been established in order to determine the real duration of the test. It is found out in [3] that after 40 days of exposure the obtained mass loss is realistic for simulating the natural corrosion damage.

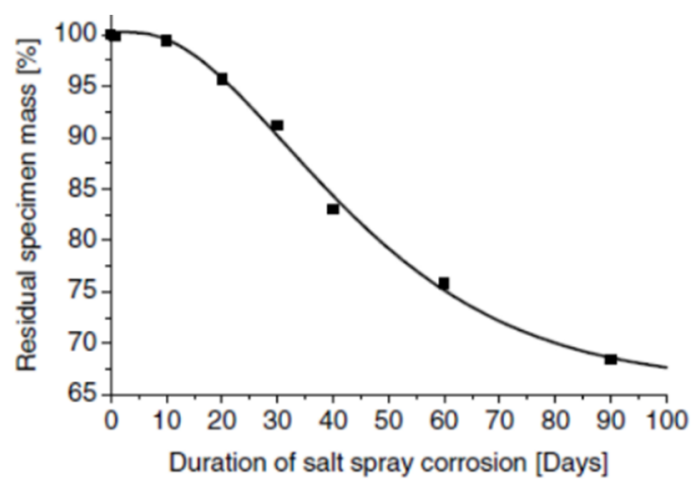

Fig. 5. Effect of salt mist exposure time on mass loss [3].

In [10] are conducted similar tests according to British standards GB/T 10125-2012 and GB/T 24517-2009. A solution of $\mathrm{NaCl}$ with $50 \mathrm{mg} . \mathrm{L}^{-1}$ (pH $6.2 \div 7.2$ ) concentration was used. Specimens were with a size of $280 \times 50 \times 8 \mathrm{~mm}$ and were divided into 8 groups depending on the time of testing $-30,110,150,250,310,370$ и 440 days. Each group included 3 standard specimens. Specimens not subjected to corrosion impact were used as a control group.

Nowadays the salt spray test is widely accepted as a method of testing paints and other anti-corrosion coatings $[9,11]$. It is also a well-known and proven fact that it has a number of drawbacks, which often bring in question the results both in coatings and in obtaining corroded specimens for mechanical testing:

- the $5 \%$ solution of $\mathrm{NaCl}$ and temperature of $35^{\circ} \mathrm{C}$ often differ significantly from real operation conditions;

- the artificial atmosphere, is constant over time whereas in a natural atmospheric environment the temperature, humidity and the other parameters describing the environment are of variable, often cyclic nature.

\subsection{Cyclic corrosion test}

Cyclic corrosion test (CCT-test) is the modern and realistic accelerated corrosion method resembling atmospheric environment. Special automatically operated chambers are used, which can control the cycles of the following parameters: temperature; humidity; wetness/ drying; concentration of the solution; ultraviolet radiation.

It is possible to program varied cycles and to simulate various operation conditions. Some of these cycles are standardized, for example ISO 16701:2015; ISO 14993: 2006; ISO 16151:2008; ISO 16539:2013. A simplified alternative is the ISO 11130:2010 - testing with periodic immersion in salt solution.

Fig. 6 illustrates the ISO 16701:2015 standard - cyclic change in temperature and humidity is combined with spraying of $1 \% \mathrm{NaCl}$ solution onto specimens for $3 \times 15$ min twice a week.

Fig. 7 shows the effect of that cycle on galvanized iron sheet after 12-week exposure [11]. A comparison was made with a sample from the same material, which was exposed to a tropical coastal climate for a year. Very similar corrosion behaviour is observed and the CCT-test with that duration shows considerably more aggressive impact. 


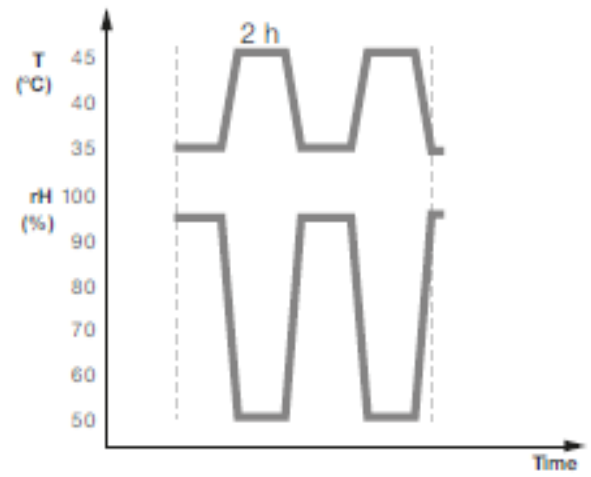

Fig. 6. Cyclic change of temperature and humidity, according to ISO 16701:2015 [11].
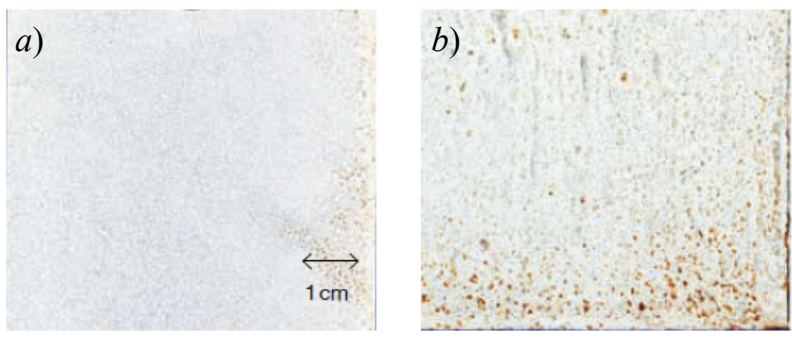

Fig. 7. Comparison of the results of natural corrosion $(a)$ and CCT-testing (b), ISO 16701:2015 [11].

\subsection{Scab testing}

Specimens are positioned southwards in the open air at an angle of $45^{\circ}$. Twice a week they are sprayed with $3 \%$ $\mathrm{NaCl}$ solution. The test can last, for example, 6 months. The testing is standardized (ISO 11474:2014).

That is the easiest method of accelerated corrosion which involves cycles of wetting/drying, changing the concentration of the solution, the temperature and the ultraviolet sun radiation. Although it is technically easy to perform, this method is slow and labor-consuming and it is not widely used.

\subsection{Imitation of corrosion}

The idea to imitate corrosion by taking away material from the surface of a specimen, with a digitally controlled drilling machine does not seem to be good. It is logical that the obtained relief will be quite different from anything that would be obtained through the process of corrosion. In reality, however, such an imitation has two great advantages:

- when an appropriate machine and a 3D geometrical model is available, specimens are obtained extremely fast, easily and cheaply;

- the obtained specimens are $100 \%$ identical with the 3D geometric models. This is quite useful for approbating computer models, simulating with the finite element method various impacts caused by corrosion. Such geometric coincidence cannot be achieved in a different way.

This technique is used in [12] to produce specimens and subject them to a tensile test as shown in Fig. 8. The strain curves obtained in the experiment were used to approbate a finite element computer model, which was then used to forecast the decrease in strength and deformability with increasing pitting corrosion. The model was used to create an empirical formula for the same purpose.
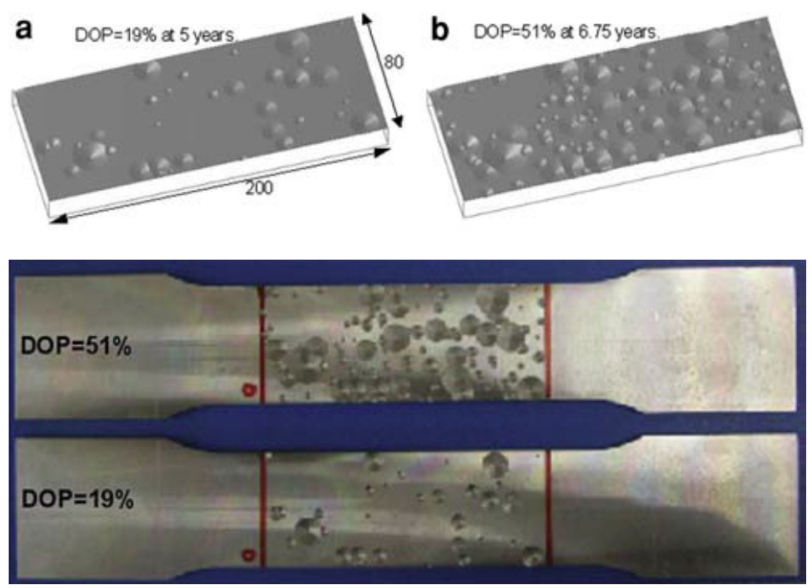

Fig. 8. Imitation of pitting corrosion by means of $\mathrm{CNC}$ drilling machine [12].

\section{Conclusion}

In order to evaluate the change in the mechanical properties of steel subjected to corrosion, it is necessary to test a series of specimens with several different but specified degrees of corrosion. The paper reviews existing methods for obtaining specimens used for mechanical testing. The review indicates that the choice of corrosion method can significantly impact specimen behaviour in tensile test and the method must be chosen very carefully. The applicability, specific features, advantages and disadvantages of each of the reviewed methods have been commented on.

\section{References}

1. R. François, I. Khan, V. Dang, Impact of corrosion on mechanical properties of steel embedded in 27-yearold corroded reinforced concrete beams, Materials and structures, 46(6), 899-910, (2013)

2. C. Apostolopoulos, V. Papadakis, Consequences of steel corrosion on the ductility properties of reinforcement bar, Construction and Building Materials, 22(12), 2316-2324, (2008)

3. C. Apostolopoulos, M. Papadopoulos, S. Pantelakis, Tensile behavior of corroded reinforcing steel bars BSt 500s, Construction and building Materials, 20(9), 782-789, (2006)

4. T. Kaita, J. Appuhamy, K. Itogawa, M. Ohga, K. Fujii, Experimental study on remaining strength estimation of corroded wide steel plates under tensile force, Procedia Engineering, 14, 2707-2713, (2011)

5. F. del Angel, Fractal effect of corrosion on mechanical behavior of unprotected structural steel, In: Developments in Corrosion Protection, 551-565, (InTech, 2014) 
6. G. Chen, M. Hadi, D. Gao, L. Zhao, Experimental study on the properties of corroded steel fibres, Construction and Building Materials, 79, 165-172, (2015)

7. H. Lee, Y. Cho, Evaluation of the mechanical properties of steel reinforcement embedded in concrete specimen as a function of the degree of reinforcement corrosion. International Journal of Fracture, 157(1-2), 81-88, (2009)

8. A. Rahbar Ranji, A. Zakeri, Mechanical properties and corrosion resistance of normal strength and high strength steels in chloride solution, J. of Naval Architecture and Marine Engineering, 7(2), 93-100, (2010)

9. D. Grossman, More realistic tests for atmospheric corrosion, Journal of Protective Coatings \& Linings, 13(9), 4, (1996)

10. G. Qin, S. Xu, D. Yao, Z. Zhang, Study on the degradation of mechanical properties of corroded steel plates based on surface topography, Journal of Constructional Steel Research, 125, 205-217, (2016)

11. HILTI Corrosion handbook, https://www.hilti.pt, Hilti Corporation, (2015)

12. M. Ahmmad, Y. Sumi, Strength and deformability of corroded steel plates under quasi-static tensile load, J. of marine science and technology, 15(1), 1-15, (2010) 